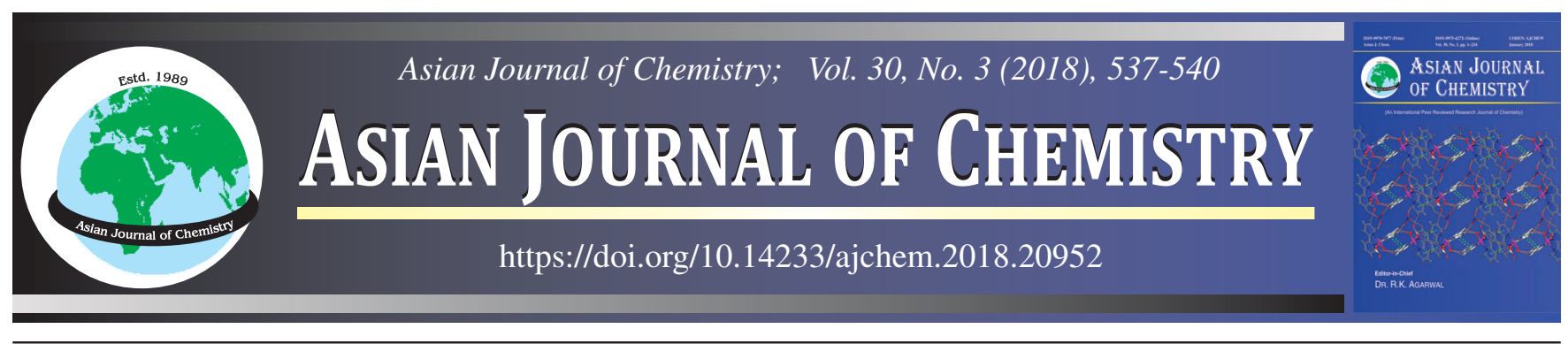

\title{
Design, Synthesis and Characterization of Biogenic Chloroquine Silver Nanoparticles as Potential Anticancer Agent against Neuroblastoma Cells
}

\section{S.C. ViVeKanandhan ${ }^{1}$, M. ChandRamohan ${ }^{2}$ and P. SELVAM ${ }^{3}, *$}

${ }^{1}$ Department of Medicine, Thoothukudi Medical College, Thoothukudi-628 008, India

${ }^{2}$ Bharat Ratna Kamarajar Jaundice Liver Hospital and Research Centre, Madurai-625 001, India

${ }^{3}$ Sir CV Raman-K.S. Krishnan International Research Centre, Kalasalingam University, Krishnankoil-626 126, India

*Corresponding author: Fax: +91 4563 289322; E-mail: selvaamin@gmail.com

Received: 4 August 2017;

Accepted: 20 October 2017;

Published online: 31 January 2018;

AJC-18739

\begin{abstract}
Chloroquine (4-aminoquinoline derivative) an old antimalarial drug is a versatile bioactive agent and reported to have board spectrum of activity including anticancer and antiviral activity and firmly repositioned in these latter indications. In literature report of chloroquine retinopathy upto $0.5 \%$ was noted to circumvent this toxicity and increase the efficacy of the drug. We ventured to develop a novel approach of the green synthesis of chloroquine silver nanoparticles and anticancer activity of the same was tested by MTT against Neuroblastoma (SH-SY5Yc) and cytotoxicity was also investigated against normal Vero cells by MTT assay. We prepared chloroquine silver nanoparticles by an ecofriendly method and was characterized using FT-IR, UV-visible, SEM and PXRD techniques. Anticancer activity of chloroquine silver nanoparticles was tested against Neuroblastoma (SH-SY5Yc) by MTT assay and cytotoxicity in vero cells The UV-visible spectrum for prepared silver nanoparticles shows sharp peak at $434 \mathrm{~nm}$ confirms the presence of silver nanoparticles. SEM analysis showed that the nanoparticles are spherical in shape and average size of the particles are $254 \mathrm{~nm}$. Powder XRD studies, $2 \theta$ value (220), (111), (211) confirms that the biosynthesized nanoparticles are in crystalline nature. The prepared chloroquine silver nanoparticles showed significant anticancer activity against Neuroblastoma cells by MTT assay with inhibitory concentration $\left(\mathrm{IC}_{50}\right)$ of $33.79 \mu \mathrm{g} / \mathrm{mL}$, where as cytotoxicity $\left(\mathrm{CC}_{50}\right)$ of chloroquine silver nanoparticles in Vero cells was found to be $173.79 \mu \mathrm{g} / \mathrm{mL}$.
\end{abstract}

Keywords: Chloroquine, Silver nanoparticles, Anticancer Activity, Neuroblastoma cells.

ᄂ - - - - - - - - - - - - - - - - - - - - - - - - - - - - - - -

\section{INTRODUCTION}

Cancer is a major threat to human health and enormous drugs in the market for the treatment of cancer. However, the cancer cells could develop rapid resistance to approved drugs due to high mutation rate. In order to overcome the resistance, new drugs with novel molecular mechanisms of action should be developed and recently much attention has been devoted for searching of potential anticancer agents. Chloroquine phosphate (CQ) is a versatile therapeutic agents and approved as antimalarial agent also, used for treatment of amoebiasis, rheumatoid arthritis, lupus erythematosus, photo allergic disorder, as a non specific anti-inflammatory agent. Chloroquine (CQ) also reported for board-spectrum antiviral activity [1] against HIV [2], HBV [3], HCV [4,5], influenza [6], dengue [7], SARS-CoV [8] and chikungunya virus [9].

Chloroquine reported for anticancer activity [10-12] and also enhancing anticancer activity of radiotherapy [13]. Mechanism of anticancer activity of chloroquine in by inhibiting autophagy and activating apoptosis [14,15]. Chloroquine causes central nervous system toxicity of retinopathy and epilepsy up to 25 to $40 \%$ in rheumatoid arthritis patients at 20 $\mathrm{mg} / \mathrm{kg}$ dosage for prolonged period [16-18] and nanoparticles may reduce the same. Current work is to biosynthesis and characterization of the chloroquine silver nanoparticles (CQ AgNPs) and tested anticancer activity against Neuroblastoma (SH-SY5Yc) and cytotoxicity was also investigated against normal Vero cells by MTT assay.

\section{EXPERIMENTAL}

Preparation of silver nanoparticles: Silver nitrate $\left(\mathrm{AgNO}_{3}\right)$ was obtained from Hi Media (Mumbai, India). Aqueous solution of $1 \mathrm{mM} \mathrm{AgNO}$ was used for the synthesis of silver nanoparticles. The $50 \mathrm{~mL}$ of silver nitrate solution was stirred for $10 \mathrm{~min} .10 \mathrm{mg}$ of Chloroquine was dissolved in ethanol and $0.5 \mathrm{~mL}$ of chloroquine solution was added to silver nitrate solution drop by drop continuously which was under stirring at $40^{\circ} \mathrm{C}$. After $30 \mathrm{~min}$ the solution changes to reddish brown in colour. Colour change from colourless to reddish brown indicates the formation of chloroquine silver nanoparticles. 
Characterization of silver nanoparticles: UV-visible spectra of the silver nanoparticles obtained from chloroquine for plasmon resonance band analyzed in Shimadzu Double beam UV-visible spectrophotometer. The scanning electron microscopy (SEM) analysis was carried by a Carl Zeiss EVO-18 electron micro-scope and visualized the morphological size and shape. A sample of a nanoparticles solution was placed on a carbon strip attached to a SEM brass, extra solution was detached using blotting paper and then allowed to dry by putting it under a mercury lamp for $5 \mathrm{~min}$. The elemental compositions of chloroquine silver nanoparticles were obtained using BRUKER EDS(QUANTAX 200-XFLASH) SDD (silicon drift detector) by variable pressure mode, at acceleration voltage of $20 \mathrm{KeV}$. The Fourier transform infrared spectra were recorded using IR Tracer-100 Shimadzu, FTIR and using the spectral range $4000-400 \mathrm{~cm}^{-1} .50 \mathrm{mg}$ chloroquine silver nanoparticles placed in ATR diamond disc (zinc selenide) for FTIR measurement. The crystalline and the lattice characteristics of the synthesized silver nanoparticles were measured by powder X-ray diffraction analyzed. The XRD measurement was carried out on thoroughly dried thin films of the purified chloroquine silver nanoparticles was dried on a glass slab on a D8 Advance ECO XRD Systems with SSD160 1D Detector-Bruker XRD 6000 instrument operated at a voltage of $20 \mathrm{keV}$ and a current of 30 $\mathrm{mA}$ with $\mathrm{CuK}_{\alpha 1}$ radiation $(\lambda=0.1542)$ in a $2 \theta\left(^{\circ}\right)$ configuration. The particle size of chloroquine silver nanoparticles were determined by using Beckman coulter particle size analyzer (Delsa ${ }^{\mathrm{TM}}$ Nano common).

Anticancer activity and cytotoxicity: Chloroquine silver nanoparticles were investigated for the anticancer activity against Neuroblastoma cell (SH-SY5Y cells), cytotoxicity also tested against Vero cells by MTT assay [19]. $50 \%$ inhibitory concentration $\left(\mathrm{IC}_{50}\right)$ and $50 \%$ cytotoxic concentrations $\left(\mathrm{CC}_{50}\right)$ were measured in $\mu \mathrm{g} / \mathrm{mL}$ to understand the anticancer activity and cytotoxicity effect, respectively.

\section{RESULTS AND DISCUSSION}

In the present work, authors synthesized silver nanoparticles by bioreduction method using silver nitrate solution as a source and chloroquine as a reducing agent. The process of silver nanoparticles generation is presented in Fig. 1a. In brief, the chloroquine added to the source solution and the mixture was stirred on a magnetic stirrer till colour changed to reddish brown. The colour change indicate the reduction of silver nitrate to silver nanoparticles. The UV-visible spectrum for prepared silver nanoparticles shows noticeable absorptions maximum at $434 \mathrm{~nm}$, confirms the presence of silver nanoparticles and also absorptions maximum same upto $5 \mathrm{~h}$ (Fig. 1b). The SEM studies used to investigate the morphology of the silver nanoparticles and from SEM images confirms that the prepared nanoparticles in spherical shape and their morphology are shown in the Fig. 2. Fig. 3 revealed three peaks at degree $2 \theta$ $28.2^{\circ}, 32.7^{\circ}$ and $38.2^{\circ}$ corresponding to three diffraction from (220), (111), (211) planes of silver (as correlated to JCPDS: File No. 4-783). The XRD studies show that biosynthesized nanoparticles are crystalline in nature. Chloroquine silver nanoparticles silver nanoparticles were of the sizes range from $17-400 \mathrm{~nm}$ and average size of the particles is $254 \mathrm{~nm}$ (Fig. 4).

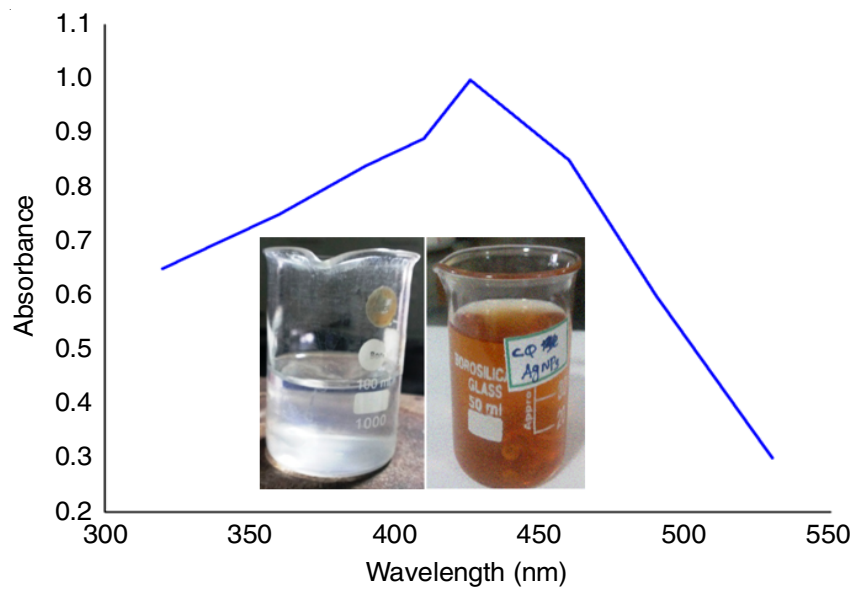

Fig. 1a. UV-visible spectra of chloroquine silver nanoparticles at $30 \mathrm{~min}$

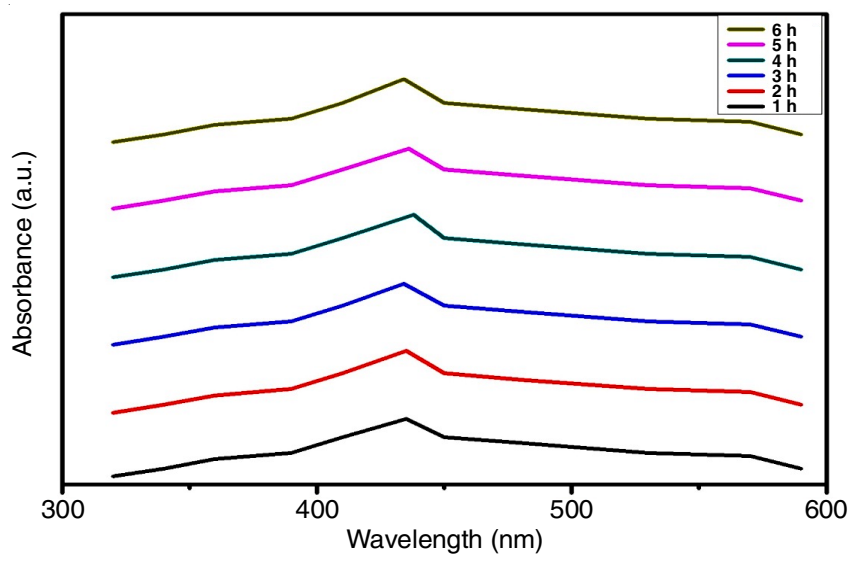

Fig. 1b. UV-visible spectra of chloroquine silver nanoparticles at $1-5 \mathrm{~h}$
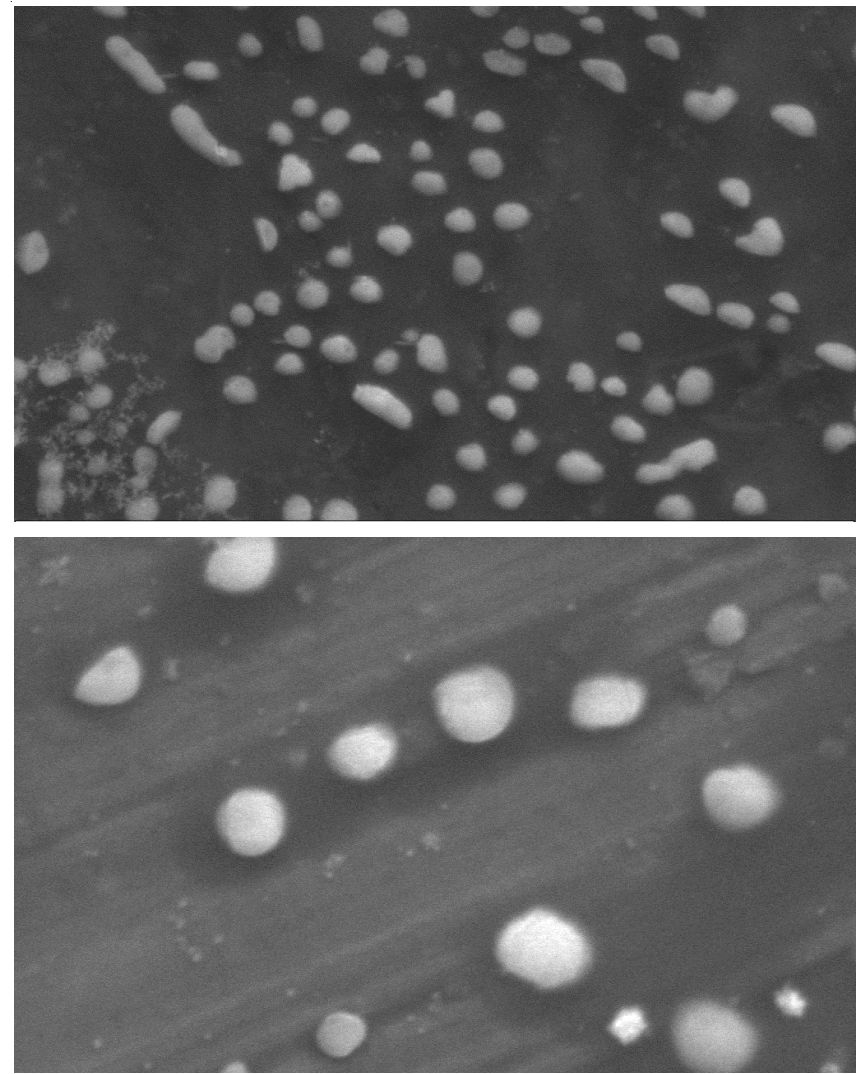

Fig. 2. SEM analysis of chloroquine silver nanoparticles 


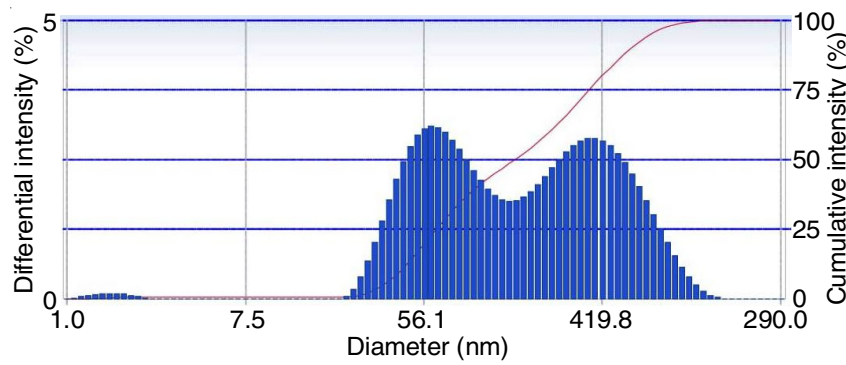

Fig. 3. Particle size analysis of chloroquine silver nanoparticles

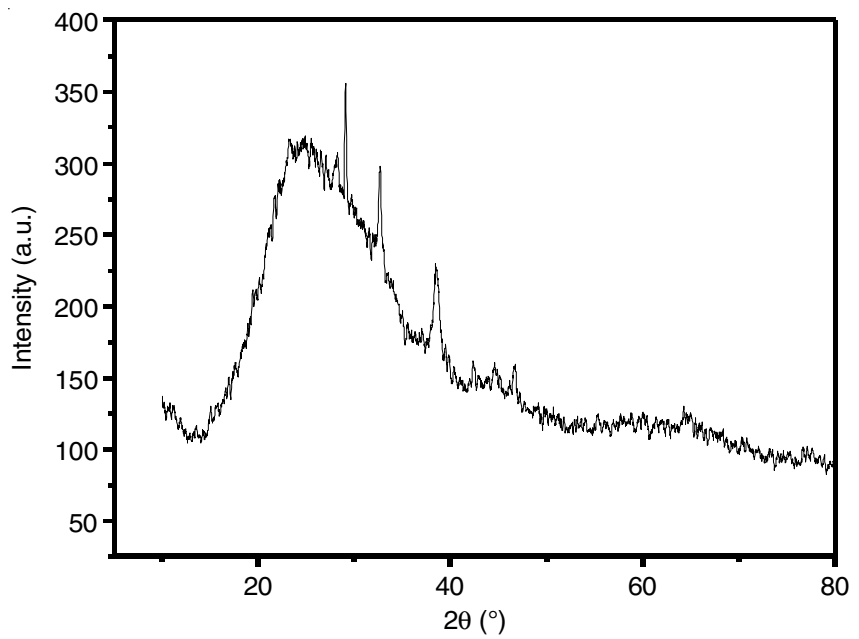

Fig. 4. XRD analysis of chloroquine silver nanoparticles

Polydispersity index was found to be 0.208 , this indicates no nanoparticles aggregation and mono disperse of synthesized nanoparticles. IR spectrum indicates (Fig. 5) the broad band at near $3500 \mathrm{~cm}^{-1}$ shows the presence of N-H group and 2968 and $2929 \mathrm{~cm}^{-1}$ is for C-H stretching. The frequencies $900-690$ $\mathrm{cm}^{-1}$ is for $=\mathrm{C}-\mathrm{H}$ bending occurs out of plane. 1610 and 1452 $\mathrm{cm}^{-1}$ is for the $\mathrm{C}=\mathrm{C}$ ring stretch also $1579 \mathrm{~cm}^{-1}$ is for the N-H and $\mathrm{C}-\mathrm{N}$ stretching in the spectrum.

The prepared chloroquine silver nanoparticles showed significant anticancer activity against Neuroblatoma cells with inhibitory concentration $\left(\mathrm{IC}_{50}\right)$ of $33.79 \mu \mathrm{g} / \mathrm{mL}$, whereas cytotoxicity $\left(\mathrm{CC}_{50}\right)$ of AgNPs in Vero cells was found to be $173.79 \mu \mathrm{g} / \mathrm{mL}$ both by MTT assay (Figs. 6a,b and 7).

\section{Conclusion}

Chloroquine nanoparticles were reported for anticancer activity with inhibition of autophagy [20,21], antimalarial and

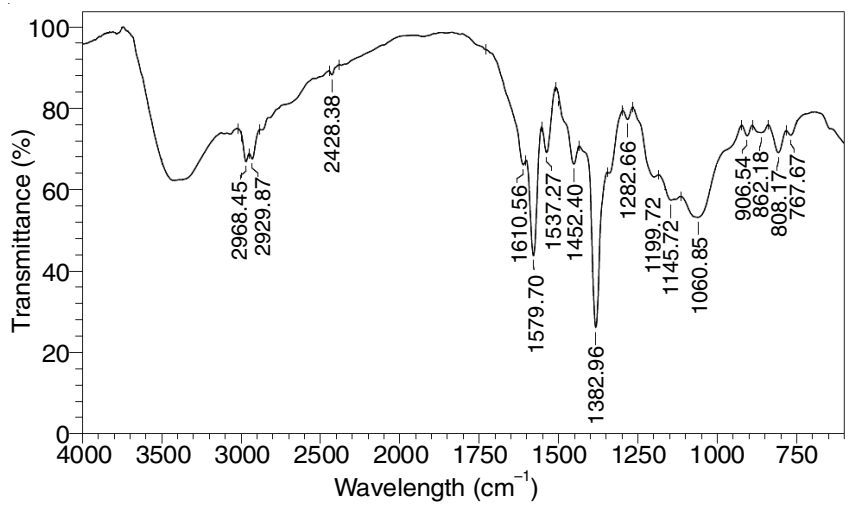

Fig. 5. FT IR spectrum of chloroquine silver nanoparticles

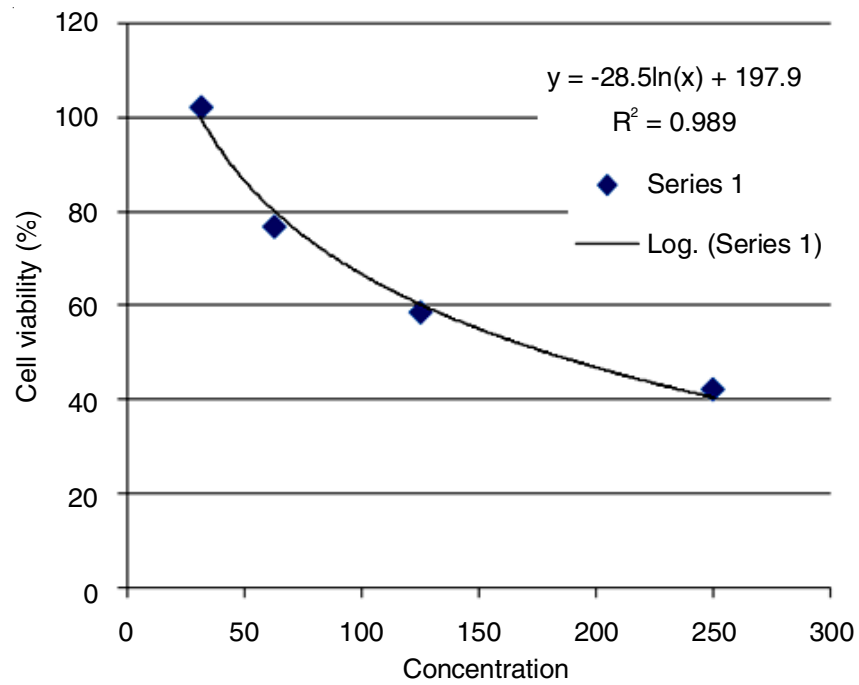

Fig. 6a. Cytotoxicity of chloroquine silver nanoparticles in Vero cells

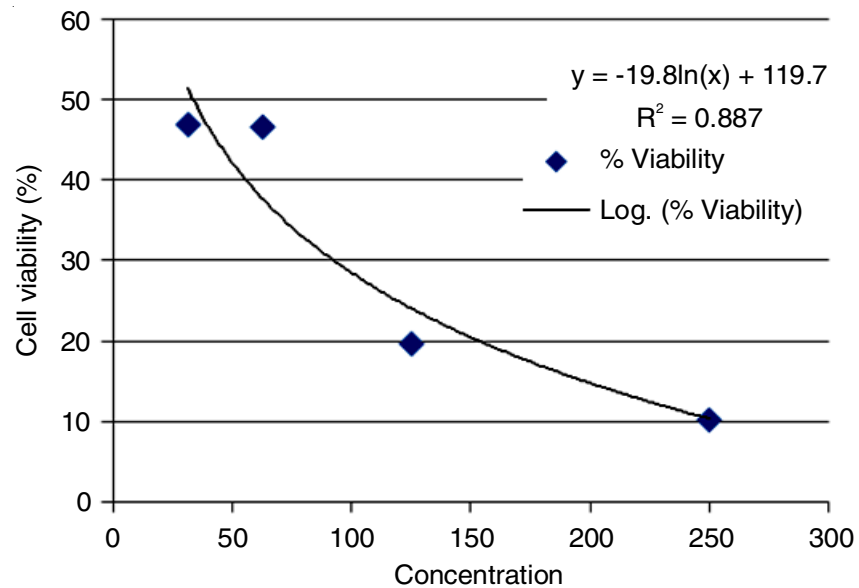

Fig 6b. Anticancer activity of chloroquine silver nanoparticles in Neuroblastoma cells

antidengue virus activities [22,23]. We have successfully synthesized silver nanoparticles using chloroquine as a reducing agent and the prepared nanoparticles were confirmed by the characterization technique UV-visible, FTIR, SEM and XRD. We have shown the anticancer potential of chloroquine silver nanoparticles and the inhibitory concentration $\left(\mathrm{IC}_{50}\right.$ ) of $33.79 \mu \mathrm{g} / \mathrm{mL}$.

\section{ACKNOWLEDGEMENTS}

The authors sincerely thank Dr. Ashish Wadhwani, Head, Department of Pharmaceutical Biotechnology, JSS College of Pharmacy, Uthagamandalam, India for cytotoxicity studies.

\section{REFERENCES}

1. J.M. Rolain, P. Colson and D. Raoult, Int. J. Antimicrob. Agents, 30, 297 (2007);

https://doi.org/10.1016/j.ijantimicag.2007.05.015.

2. M.R. Fesen, K.W. Kohn, F. Leteurtre and Y. Pommier, Proc. Natl. Acad. Sci. USA, 90, 2399 (1993); https://doi.org/10.1073/pnas.90.6.2399.

3. G. Civitico, Y.Y. Wang, C. Luscombe, N. Bishop, G. Tachedjian, I. Gust and S. Locarnini, J. Med. Virol., 31, 90 (1990); https://doi.org/10.1002/jmv.1890310205.

4. M. Chandramohan, S.C. Vivekananthan, D. Sivakumar, P. Selvam, J. Neyts, G. Katrien and E. De Clercq, Indian J. Pharm. Sci., 68, 538 (2006); https://doi.org/10.4103/0250-474X.27842. 


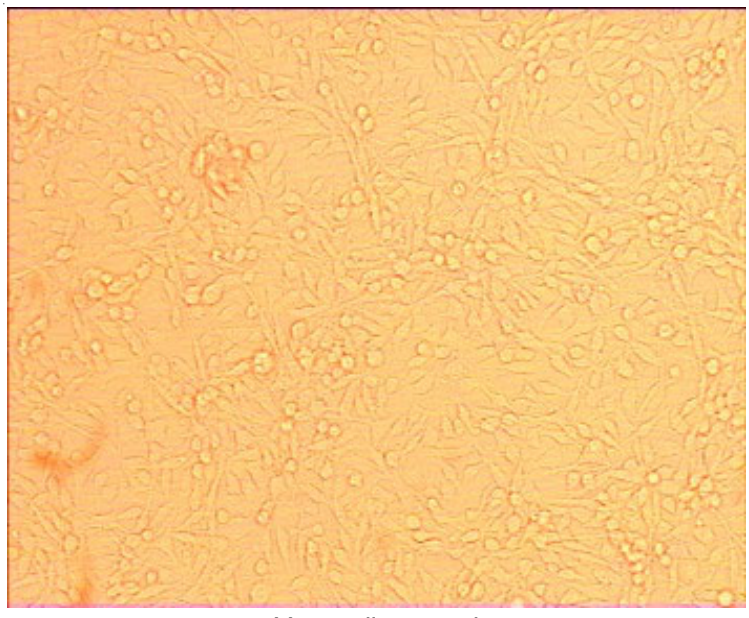

Vero cells normal

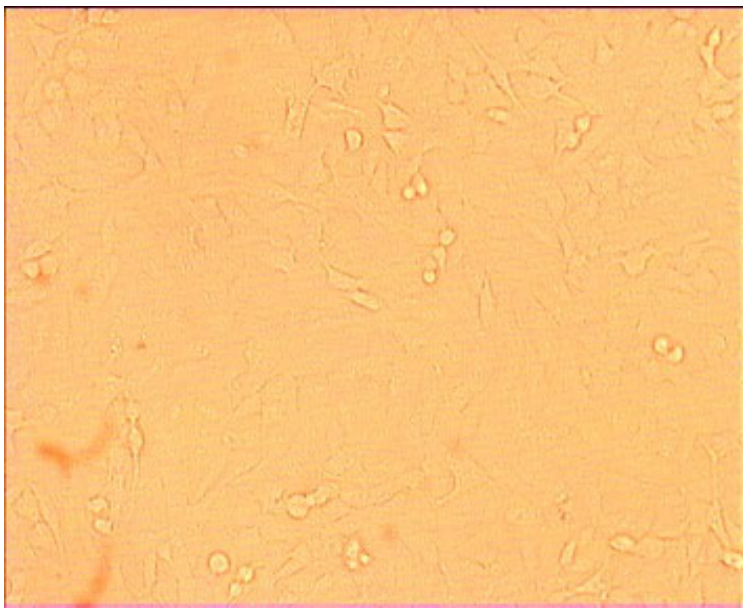

Neuroblastoma cells normal

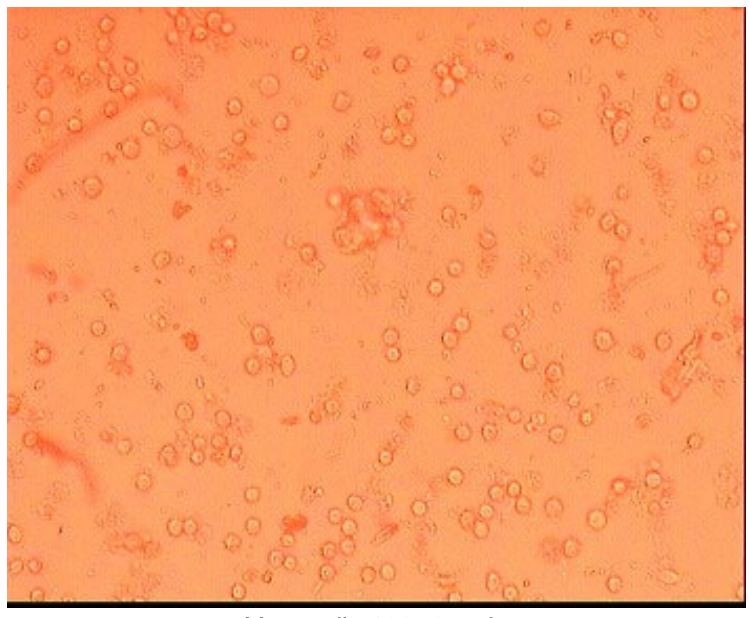

Vero cells $100 \%$ toxic

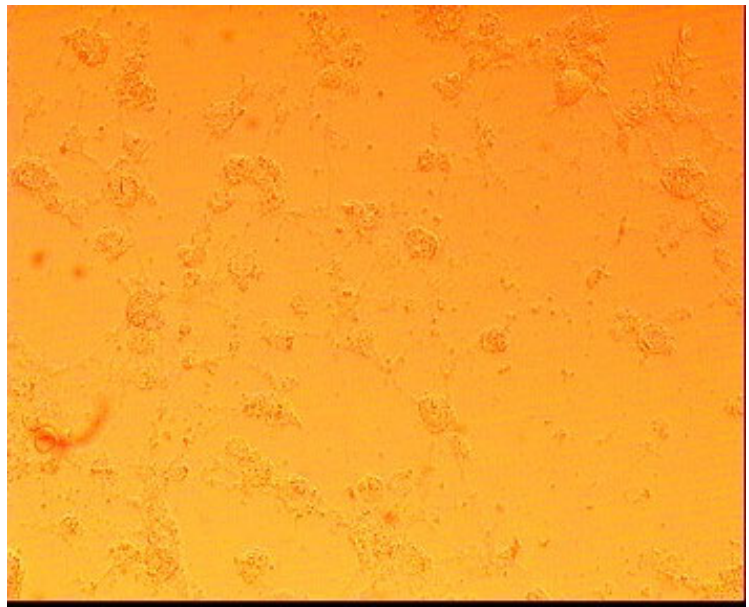

Neuroblastoma cells $100 \%$ toxic

Fig. 7. Anticancer activity and cytotoxicity of chloroquine silver nanoparticles

5. U.A. Ashfaq, T. Javed, S. Rehman, Z. Nawaz and S. Riazuddin, Virol. J., 8, 163 (2011);

https://doi.org/10.1186/1743-422X-8-163.

6. N.I. Paton, L. Lee, Y. Xu, E.E. Ooi, Y.B. Cheung, S. Archuleta, G. Wong and A.W. Smith, Lancet Infect. Dis., 11, 677 (2011); https://doi.org/10.1016/S1473-3099(11)70065-2.

7. K.J. Farias, P.R. Machado, J.A. Muniz, A.A. Imbeloni and B.A. Da Fonseca, Viral Immunol., 28, 161 (2015); https://doi.org/10.1089/vim.2014.0090.

8. E. Keyaerts, L. Vijgen, P. Maes, J. Neyts and M.V. Ranst, Biochem. Biophys. Res. Commun., 323, 264 (2004); https://doi.org/10.1016/j.bbrc.2004.08.085.

9. M. Khan, S.R. Santhosh, M. Tiwari, P.V. Lakshmana Rao and M. Parida, J. Med. Virol., 82, 817 (2010); https://doi.org/10.1002/jmv.21663.

10. S. Hatziieremia, P. McCall, J. Willder, C. Orange, M. Seywright, M.A. Underwood and J. Edwards, Cancer Res., 73, 1 (2013); https://doi.org/10.1158/1538-7445.AM2013-1.

11. M. Gwenola, O. Florine, K. Guido, V. Illio and G. Lorenzo, Mol. Cel. Oncol., e29911 (2014); https://doi.org/10.4161/mco.29911.

12. V. Solomon and H. Lee, Eur. J. Pharmacol., 625, 220 (2009); https://doi.org/10.1016/j.ejphar.2009.06.063.

13. Y.C. Lin, J.F. Lin, S.I. Wen, S.C. Yang, T.F. Tsai, H.E. Chen, K.Y. Chou and T.I. Hwang, Kaohsiung J. Med. Sci., 33, 215 (2017); https://doi.org/10.1016/j.kjms.2017.01.004.

14. M.E. Egger, J.S. Huang, W. Yin, K.M. McMasters and L.R. McNally, J. Surg. Res., 184, 274 (2013); https://doi.org/10.1016/j.jss.2013.04.055.

15. H. Zhao, Y. Liao, D. Xu, Q. Wang, Q. Gan, C. You and C. Yang, BMC Neurol., 16, 1 (2016); https://doi.org/10.1186/s12883-015-0524-9.
16. M.F. Marmor, U. Kellner, T.Y. Lai, R.B. Melles and W.F. Mieler, Am. Acad. Ophthalmol., 123, 1386 (2016); https://doi.org/10.1016/j.ophtha.2016.01.058.

17. L.S. Leung, J.W. Neal, H.A. Wakelee, L.V. Sequist and M.F. Marmor, Am. J. Ophthalmol., 160, 799 (2015); https://doi.org/10.1016/j.ajo.2015.07.012.

18. E.V. Navajas, H. Krema, D.S. Hammoudi, J.H. Lipton, E.R. Simpson, S. Boyd and M. Easterbrook, Can. J. Ophthalmol., 50, 442 (2015); https://doi.org/10.1016/j.jcjo.2015.08.003.

19. P. Skehan, R. Storeng, D. Scudiero, A. Monks, J. McMahon, D. Vistica, J.T. Warren, H. Bokesch, S. Kenney and M.R. Boyd, J. Natl. Cancer Inst., 82, 1107 (1990): https://doi.org/10.1093/jnci/82.13.1107.

20. P. Joshi, S. Chakraborty, S. Dey, V. Shanker, Z.A. Ansari, S.P. Singh and P. Chakrabarti, J. Colloid Interf. Sci., 355, 402 (2011); https://doi.org/10.1016/j.jcis.2010.12.032.

21. P. Joshi, S. Chakraborti, J.E. Ramirez-Vick, Z.A. Ansari, P. Chakraborti and S.P. Singh, Colloids Surf. B Biointerf., 15, 195 (2012); https://doi.org/10.1016/j.colsurfb.2012.02.039.

22. S. Tripathy, S. Das, S.P. Chakraborty, S.K. Sahu, P. Pramanik and S. Roy, Int. J. Pharm., 434, 292 (2012); https://doi.org/10.1016/j.ijpharm.2012.05.064.

23. K. Murugan, J. Wei, M.S. Alsalhi, M. Nicoletti, M. Paulpandi, C.M. Samidoss, D. Dinesh, B. Chandramohan, C. Paneerselvam, J. Subramaniam, H. Wei, C. Vadivalagan, P. Amuthavalli, A. Jaganathan, S. Devanesan, A. Higuchi, S. Kumar, A.T. Aziz, D. Nataraj, B. Vaseeharan, A. Canale and G. Benelli, Parasitol. Res., 116, 495 (2017); https://doi.org/10.1007/s00436-016-5310-0. 